\title{
Kepemimpinan Kolaboratif : Sebuah Bentuk Kepemimpinan Untuk Sekolah
}

\author{
Yuni Kasmawati \\ Fakultas Ekonomi dan Bisnis Universitas Budi Luhur \\ Email : yuni.kasmawati@budiluhur.ac.id
}

\begin{abstract}
Changes that occur due to globalization need to be managed by leaders in order to achieve organizational goals. The way leaders manage change is influenced by the environment. Therefore, the style in leading an organization requires adaptation. Today, collaborative leadership is needed to cope with rapid change. Likewise the leadership of a school. The literature review method was chosen for the analysis of this study. Books, journals and other forms of publication are used as reference sources. This study provides an overview of collaborative leadership that needs to be applied in dealing with change for the success and effectiveness of schools, including for teachers and students.
\end{abstract}

Keywords : Collaborative Leadership, Leadership, School

Abstrak. Perubahan yang terjadi akibat globalisasi perlu dikelola pimpinan demi tercapainya tujuan organisasi. Cara pemimpin mengelola perubahan dipengaruhi oleh lingkungan. Oleh karena itu, gaya dalam memimpin suatu organisasi membutuhkan adaptasi. Saat ini, kepemimpinan kolaboratif dibutuhkan untuk mengatasi perubahan yang cepat. Begitu juga kepemimpinan suatu sekolah. Metode tinjauan literatur dipilih untuk analisis penelitian ini. Buku, jurnal maupun bentuk publikasi lainnya digunakan sebagai sumber referensi. Penelitian ini memberi gambaran umum tentang kepemimpinan kolaboratif yang perlu diterapkan dalam menghadapi perubahan demi keberhasilan dan keefektifan sekolah termasuk bagi guru dan siswa.

Kata Kunci : Kepemimpinan Kolaboratif, Kepemimpinan, Sekolah

\section{PENDAHULUAN}

Sumber daya manusia dapat ditingkatkan antara lain melalui pendidikan Jalur formal, non formal maupun informal bisa dipilih dalam pendidikan. Sekolah merupakan lembaga pendidikan formal yang secara khusus dirancang untuk mendidik siswa melalui pengawasan guru. Secara umum, sekolah merupakan sarana untuk membentuk siswa menjadi manusia yang mempunyai kepribadian dan intelektual tinggi sehingga mampu berkontribusi dalam membangun dan mencerdaskan bangsa.

Era industri 4.0 yang ditandai dengan otomatisasi dan digitalisasi memberi konsekuensi bagi pengelola pendidikan khususnya kepala sekolah untuk menyelaraskan semua kerangka sendi dan kerangka kerja pendidikan sesuai kebutuhan pasar. Peran kepala sekolah dalam membentuk siswa untuk memiliki kompetensi di era industri 4.0 menjadi semakin dibutuhkan. Hal ini mengingat bahwa kompetensi siswa seperti pemikiran kritis, kreatif, inovatif, kolaboratif dan komunikatif diperlukan untuk menjadi sumber daya manusia yang unggul dan mampu bersaing di era industri 4.0.

Tuntutan masyarakat terhadap sekolah untuk berkinerja lebih tinggi dan unggul secara akademis telah memusatkan perhatian pada peran penting kepemimpinan. Seorang pemimpin sekolah yang sukses akan menciptakan lingkungan yang mendukung pengajaran dan pembelajaran menjadi efektif serta membangun kapasitas untuk pembelajaran (Robinson et al., 2008), bahkan kepemimpinan bisa dijadikan katalisator untuk perbaikan sekolah (Hallinger dan Heck, 2010a). Sebagai penentu keberhasilan sekolah, penelitian Heck dan Hallinger (2005) menyimpulkan bahwa kepemimpinan berkontribusi pada peningkatan sekolah khususnya pada pembelajaran siswa. Demikian juga Leithwood et al. (2019) mengklaim bahwa kepemimpinan sekolah mempunyai pengaruh kedua 
setelah pengajaran terhadap pembelajaran siswa. Selanjutnya kepemimpinan tersebut memiliki pengaruh yang lebih besar pada sekolah dan siswa jika didistribusikan secara luas. Oleh karena itu, pemimpin sekolah perlu upaya melibatkan setiap personel sekolah untuk memperhatikan, menghadapi, melaksanakan tugas pengajaran dan memobilisasi sumber daya yang dibutuhkan untuk mendukung transformasi pengajaran dan pembelajaran (Spillane et al., 2007).

Saat ini, sekolah menghadapi situasi yang semakin kompleks seperti adanya ketidakpastian, keragaman, tuntutan terhadap guru dan siswa untuk meningkatkan hasil akademik serta harapan yang tinggi dalam berinovasi dan reformasi. Dalam menghadapi situasi seperti ini, model kepemimpinan yang berfokus pada kepala sekolah bukan pilihan yang terbaik (Schlebusch, 2020), pemimpin sekolah perlu mengadopsi bentuk kepemimpinan yang lebih kolaboratif (Meyer, 2009) dengan melibatkan guru, siswa dan pemangku kepentingan dalam kepemimpinannya (Hallinger, 1992).

Kepemimpinan kolaboratif merupakan cara yang praktis dan efektif untuk mengatasi masalah dan tantangan yang kompleks tersebut (Wilson, 2013). Kompleksitas yang terjadi akan mendorong kolaborasi dalam rangka pencapaian tujuan bersama. Masalah komplek lain seperti tututan untuk selalu berubah sesuai kebutuhan pasar, menjadikan kepemimpinan kolaboratif sebagai fitur fundamental dalam menghadapi perubahan, tidak terkecuali perubahan kurikulum dan implementasinya (Edwards dan Smit, 2008). Tuntutan perubahan tersebut menyebabkan semua pihak perlu berinovasi. Terkait dengan hal tersebut, kepemimpinan kolaboratif merupakan elemen yang penting dalam proses kreasi bersama untuk mendorong perubahan dan mengelola masalah yang dihadapi (Jäppinen, 2013), bahkan kepemimpinan kolaboratif memainkan peran penting dalam keberhasilan sekolah (Edwards dan Smit, 2008).

Kepemimpinan suatu sekolah harus berfokus pada proses inti dan tujuan pendidikan yaitu pengajaran, pembelajaran dan prestasi siswa (Grissom dan Loeb, 2011). Kepala sekolah bertanggung jawab terhadap penciptaan lingkungan pedagogik yang sesuai dan lingkungan yang mendukung implementasi kurikulum secara efektif dan efisien (Edwards dan Smit, 2008). Di Indonesia, kepala sekolah mempunyai tugas pokok yang berkaitan dengan manajerial, supervisi guru, pengembangan kewirausahaan dan supervisi tenaga kependidikan (Permendikbud Nomor 6 tahun 2018). Peran tersebut ditujukan untuk pengembangan dan peningkatan kualitas sekolah dengan mengacu pada delapan (8) standar pendidikan nasional. Dengan demikian kepala sekolah mempunyai posisi strategis untuk mengelola keberlangsungan suatu sekolah. Kepala sekolah dituntut mempunyai pemikiran, sikap dan perilaku yang ekstra dalam menghadapi masalah yang tidak hanya berkaitan dengan akademik tetapi juga non akademik, baik di dalam atau di luar lingkungan sekolah. Tugas dan peran kepala sekolah menjadi lebih berat manakala terjadi perubahan tidak terkecuali perubahan kurikulum sekolah. Perubahan kurikulum sekolah di Indonesia sudah terjadi beberapa kali. Misalnya perubahan perubahan kurikulum 2006 menjadi kurikulum 2013. Implementasi kurikulum 2013 tersebut dilakukan secara bertahap dan di tahun 2020 diharapkan semua sekolah sudah menerapkannya. Adanya perubahan kepemimpinan dalam kementrian pendidikan dan kebudayaan pada tahun 2019, memberi dampak pada perubahan kurikulum. Kurikulum merdeka belajar menggantikan kurikulum 2013 yang direncanakan akan diterapkan mulai tahun ajaran 2021/2022 (www.depoedu.com, 2020). Namun, Pandemi Covid-19 yang sedang melanda Indonesia tahun 2020 menjadikan pemerintah membuat kebijakan baru dengan memberlakukan kurikulum baru yaitu kurikulum darurat untuk mengantisipasi sistem pembelajaran berbasis online (www.liputan6.com, 2020). Perubahan kurikulum yang relatif cepat memberi konsekuensi bagi kepala sekolah untuk segera bertindak agar implementasi kurikulum dapat berjalan dengan baik. Suatu kepemimpinan kolaboratif akan melibatkan guru, administrasi, orang tua dan pemangku kepentingan dalam mengambil keputusan untuk menentukan langkahlangkah implementasi kurikulum agar efektif. Misalnya bersama dengan guru merancang program pembelajaran dengan mengoptimalkan pemanfaatan teknologi untuk menyesuaikan kondisi darurat akibat pandemi Covid 19. Demikian juga dukungan kepala sekolah akan terciptanya kerjasama antara guru, siswa dan orang tua dapat membantu proses pembelajaran dengan kurikulum baru berjalan dengan baik. 
Terkait dengan perubahan-perubahan yang terjadi termasuk perubahan kurikulum sekolah, tuntutan masyarakat terhadap kualitas sekolah dan tuntutan kebutuhan pasar seperti pemikiran kritis, kreatif, inovatif, kolaboratif dan komunikatif, maka tujuan artikel ini yaitu mengkaji peran kepemimpinan kolaboratif dalam mengantisipasi globalisasi untuk kesuksesan sekolah. Banyak penelitian yang mengkaji mengenai peran kepemimpinan kolaboratif dan pengaruhnya terhadap sekolah, namun penelitian-penelitian tersebut lebih banyak dilakukan di luar Indonesia. Oleh karena itu, kajian literatur ini perlu dilakukan khususnya di Indonesia sebagai bahan referensi bagaimama penerapan kepemimpinan kolaboratif mampu mendukung peningkatan kualitas sekolah. Pada akhirnya, kepala sekolah perlu menerapkan kepemimpinan kolaboratif di semua jenjang pendidikan dalam rangka mewujudkan keberhasilan pendidikan secara menyeluruh.

Kepemimpinan adalah proses mempengaruhi seseorang untuk pencapaian yang diinginkan (Bush dan Glover, 2014). Ada tiga dimensi kepemimpinan yang diusulkan oleh Bush dan Glover (2003) yaitu (1) kepemimpinan adalah proses mempengaruhi dalam rangka menyusun dan mengatur suatu organisasi, (2) kepemimpinan terkait dengan nilai-nilai organisasi dan membuat orang berkomitmen pada nilai-nilai tersebut, (3) visi merupakan komponen penting dalam kepemimpinan yang efektif. Dalam pendidikan, kepemimpinan merupakan suatu proses mempengaruhi guru dan pemangku kepentingan lainnya serta tidak harus terbatas pada satu orang (Daniëls et al., 2019). Selanjutnya dijelaskan bahwa proses pengaruh tersebut idealnya mengarah pada iklim pembelajaran yang efektif dan menjaga agar semua proses organisasi di sekolah berjalan lancar.

Literatur menekankan dampak kepemimpinan terhadap efektifitas sekolah (Hitt dan Tucker, 2016; Day dan Sammons, 2013). Misalnya, sebagai pemimpin suatu sekolah, kepala sekolah mempunyai potensi dalam meningkatkan lingkungan belajar bagi guru dan siswa, mampu meningkatkan hasil belajar melalui pengaruhnya terhadap guru maupun melalui kebijakan dan proses organisasi (Hitt dan Tucker, 2016). Kepala sekolah mampu meningkatkan prestasi belajar siswa melalui guru dengan meningkatkan dan mendukung pengajaran dan pembelajaran (Day dan Sammons, 2013). Oleh karenanya, keplala sekolah harus fokus pada proses inti sekolah seperti kurikulum dan pengajaran, pembentukan iklim dan budaya sekolah, menjaga hubungan dan komunikasi yang efektif serta mempertahankan guru yang berkualitas (Daniëls et al., 2019), menentukan arah dan menciptakan pola pikir sekolah yang proaktif, mendukung dan meningkatkan motivasi serta komitmen untuk keberhasilan sekolah (Day dan Sammons, 2013).

Kepemimpinan suatu organisasi merupakan proses mempengaruhi yang melibatkan seni agar seseorang bersedia berkolaborasi untuk pencapaian tujuan bersama. Untuk itu, seorang pemimpin harus mampu memotivasi, menginspirasi dan membimbing anggota organisasi untuk menciptakan iklim yang kondusif dalam mendukung tujuan bersama tersebut (Lazaridou dan Iordanides, 2011). Kolaborasi terjadi ketika seseorang bekerja dengan orang lain baik dari dalam organisasi maupun dari organisasi luar organisasi dengan tujuan untuk memperoleh pemahaman yang jelas dan saling menguntungkan, untuk pencapaian tujuan dan hasil yang tidak dapat mereka capai dengan bekerja sendiri. Kolaborasi melibatkan pengambilan keputusan bersama dan melibatkan proses komunikasi yang transparan dan terpercaya, dimana semua pihak merasa memperoleh informasi dan dapat memberikan umpan balik dan ide kepada orang lain. (Sanaghan dan Lohndorf, 2015).

Kolaborasi diperlukan untuk menghadapi tantangan yang dihadapi organisasi termasuk sekolah misalnya untuk mengelola perubahan dan kompleksitas akibat globalisasi. Sementara itu, kepemimpinan merupakan variabel penting dalam keberhasilan atau kegagalan tata kelola kolaboratif suatu organisasi (Ansell dan Gash, 2008). Oleh karena itu, pemimpin harus mempunyai relasi tanpa batas, mampu menciptakan peluang dan mekanisme organisasi yang diperlukan utuk berbagi ide, pekerjaan dan tindakan yang lebih luas dan tanpa batas (Sanaghan dan Lohndorf, 2015) agar kolaborasi dapat tercipta. Di lingkungan pendidikan, kolaborasi yang terbentuk antara guru, orang tua dan pemangku kepentingan mampu meningkatkan pembelajaran siswa, meningkatkan komitmen dan kepercayaan anggota organisasi dengan masyarakat sekitar (Daniel, 2017).

Kepemimpinan kolaboratif digambarkan memimpin sebagai teman, bukan atasan. Kepemimpinan kolaboratif dapat menyatukan orang-orang dengan pandangan dan perspektif yang 
berbeda, mengesampingkan kepentingan pribadi, mendiskusikan masalah secara terbuka, mendukung upaya untuk menemukan cara membantu orang lain, dan memecahkan masalah yang lebih besar. Kepemimpinan kolaboratif mengacu pada budaya inklusif yang berusaha memaksimalkan bakat dan kemampuan bawahan. Jika dilakukan dengan alasan yang benar dan dengan cara yang benar, maka dapat membuka kemungkinan dan terobosan yang tidak dihasilkan oleh model kepemimpinan tradisional (Wilson, 2013).

Kepemimpinan kolaboratif merupakan kepemimpinan yang efektif dalam mengatasi perubahan, yang mana untuk mengatasinya membutuhkan kolaborasi, mendengarkan, mempengaruhi dan adaptasi (Meyer, 2009). Sehingga, kepemimpinan masa depan termasuk kepemimpinan suatu sekolah, membutuhkan pemimpin yang mampu mendorong dialog untuk pengembangan bersama, mampu memanfaatkan pengetahuan dan pemahaman praktis seluruh anggota, mampu bersikap adil dengan memberikan ruang dan waktu untuk proses kolaboratif, mampu bersikap adil dalam distribusi kekuasaan dan mampu mendorong kondisi pembelajaran yang inovatif (Jäppinen dan Ciussi, 2016). Beberapa definisi kepemimpinan kolaboratif dari berbagai sumber disajikan pada tabel 1.

Tabel 1. Definisi Kepemimpinan Kolaboratif

\begin{tabular}{|c|c|}
\hline Referensi & Kepemimpinan Kolaboratif \\
\hline Anfara et al. (2008) & $\begin{array}{l}\text { Suatu kepemimpinan yang mengacu pada inklusivitas } \\
\text { (guru, staf administrasi, orang tua dan pemangku kepentingan) } \\
\text { dalam pengambilan keputusan yang terkait dengan tujuan } \\
\text { organisasi }\end{array}$ \\
\hline $\begin{array}{l}\text { Samriangjit et al. } \\
\text { (2016 }\end{array}$ & $\begin{array}{l}\text { Proses pemikiran dan tindakan penyelenggara sekolah dalam } \\
\text { mewujudkan kerjasama yang luas, membentuk hubungan dan } \\
\text { jaringan berdasarkan visi, komitmen dan saling percaya untuk } \\
\text { memobilisasi ketrampilan dan nilai. }\end{array}$ \\
\hline $\begin{array}{l}\text { Jäppinen dan Ciussi } \\
\text { (2016) }\end{array}$ & $\begin{array}{l}\text { Usaha bersama dimana berbagai individu secara kolektif } \\
\text { terlibat dalam interaksi yang berorientasi pada tujuan bersama } \\
\text { dan mampu menciptakan sesuatu yang sinergis melalui proses } \\
\text { tersebut }\end{array}$ \\
\hline Lawrence (2017) & $\begin{array}{l}\text { Suatu kepemimpinan yang ditandai dengan visi dan nilai } \\
\text { bersama, saling ketergantungan dan tanggung jawab bersama, } \\
\text { saling menghormati, empati, ambiguitas, komunikasi yag } \\
\text { efektif dan sinergi }\end{array}$ \\
\hline
\end{tabular}

Sumber : Sumber referensi terkait

Ada 3 (tiga) peran pemimpin dalam kepemimpinan kolaboratif yang dikemukakan oleh Ansell dan Gash (2012). Pertama, pemimpin sebagai pelayan, artinya pemimpin memfasilitasi proses kolaboratif dengan membangun dan melindungi integritas proses kolaboratif. Kedua, pemimpin sebagai mediator, artinya pemimpin menfasilitasi, memediasi dan membina hubungan dengan pemangku kepentingan. Yang terakhir, pemimpin sebagai katalis, artinya pemimpin adalah seorang yang membantu pemangku kepentingan untuk mengidentifikasi dan memanfaatkan peluang untuk menciptakan nilai. Dalam hal ini, pemimpin menjadi katalisator untuk kolaborasi yang efektif dan produktif.

Keberhasilan seorang pemimpin kolaboratif dalam memimpin dipengaruhi oleh visi, ketrampilan interpersonal, ketrampilan manajerial dan kepercayaan untuk mendorong terjadinya kolaboratif (Hopkins et al., 2011). Selanjutnya visi tersebut merupakan hasil kerja kolaboratif yang berkembang dari waktu ke waktu. Sejalan dengan hal tersebut, hasil penelitian Samriangjit et al. (2016) menyimpulkan bahwa unsur visi bersama dan kepercayaan merupakan elemen terpenting dalam kepemimpinan kolaboratif, kemudian unsur penting berikutnya adalah pengambilan keputusan bersama. 
Kepemimpinan kolaboratif diterapkan dengan tujuan pertama, memungkinkan terjadinya pertumbuhan pribadi bagi karyawan. Pertumbuhan tersebut dikarenakan karyawan dilibatkan dalam banyak aktivitas kerja sehingga memperoleh pengalaman belajar di luar fungsi pekerjaan pokoknya. Kedua, kepuasan karyawan lebih besar manakala karyawan dilibatkan dalam pengembangan tujuan dan pengambilan keputusan organisasi. Tujuan yang ketiga terkait dengan peningkatan produktivitas kerja sebagai akibat terciptanya situasi di mana karyawan mampu mewujudkan potensi penuh mereka baik sebagai karyawan maupun sebagai manusia. Sedang tujuan yang terakhir yaitu kepemimpinan kolaboratif mampu mengatasi masalah-masalah dalam organisasi akibat adanya kompleksitas tugas, teknologi dan perkembangan organisasi serta kebutuhan untuk mengelola saling ketergantungan (Finh, 1977).

Penerapan kepemimpinan kolaboratif ditunjukkan dengan keterlibatan dan minat yang tinggi kepala sekolah terhadap kegiatan sekolah, dimana ciri - ciri sekolah tersebut yaitu tersedianya aturan yang tepat, adanya kerja sama dan dukungan yang berkelanjutan, tersedianya dukungan untuk pengembangan profesional dan solidaritas profesional yang konstruktif, adanya tindak lanjut dan dukungan yang cermat serta sistematis untuk siswa, keterbukaan terhadap praktik baru, terjalinnya hubungan komunitas sekolah yang positif, terciptanya proses pengambilan keputusan bersama (administrator sekolah, guru, dan orang tua) terhadap semua aktivitas sekolah (Burgaz dan Turan, 2015)

Kepemimpinan kolaoratif merupakan jenis kepemimpinan yang diperlukan untuk mendapatkan hasil melintasi batas-batas organisasi baik internal maupun eksternal. Pemimpin dituntut untuk dapat mengelola perbedaan budaya, pengalaman dan ketrampilan yang ada dalam organisasi. Oleh karena itu, pemimpin perlu menginvestasikan waktu untuk mengelolanya, siap menangani konflik secara konstruktif dan yang utama yaitu mampu berbagi kendali (Archer dan Cameron, 2013), menyelidiki namun tidak menghakimi dan menerima kritikan orang lain (Raelin, 2006). Kepemimpinan kolaboratif yang diterapkan kepala sekolah memainkan peran penting dalam membantu guru mengidentifikasi kebutuhan untuk pengembangan profesionalnya dan menemukan serta mendistribusikan sumber daya guna mendukung pengajaran dan pembelajaran (Schlebusch, 2020).

Burgaz dan Turan (2015) setuju dengan pendapat Gruenert dan Valentine bahwa kepemimpinan kolaboratif di sekolah mempunyai karakteristik umum yaitu (1) pemimpin menghargai gagasan guru, (2) pemimpin mempercayai penilaian profesional guru, (3) pemimpin meluangkan waktu untuk memuji guru yang berkinerja baik, (4) pemimpin melibatkan guru dalam proses pembuatan keputusan, (5) pemimpin memfasilitasi guru untuk bekerja sama, (6) pemimpin menginformasikan guru tentang masalah terkini di sekolah, (7) pemimpin percaya bahwa keterlibatan guru dalam pembuatan kebijakan adalah penting, (8) guru diberi penghargaan ketika menerapkan ide dan teknik baru, (9) pemimpin mendukung inovasi dalam pengajaran yang mengandung risiko dan (10) pemimpin mendorong guru untuk berbagi ide.

Beberapa sudut pandang yang dikemukakan oleh Edwards dan Smit (2008) terkait karakteristik kepemimpinan kolaboratif yaitu : pertama, kepemimpinan kolaboratif dipandang sebagai fungsi yang dilakukan, bukan posisi yang dipegang oleh satu orang. Artinya bahwa setiap orang dalam organisasi adalah seorang pemimpin dan kepemimpinan dianggap situasional, tergantung pada keadaan bukan posisi. Kedua, kepemimpinan kolaboratif berkaitan dengan peran kekuasaan dan ketidakberdayaan. Pandangan ini memberi pengertian bahwa kepala sekolah perlu merangkul profesionalisme guru dan melakukan lebih dari sekedar berbagi kekuasaan. Ketiga, kepemimpinan kolaboratif terkait erat dengan hubungan dan keuntungan dari kerja sama. Keempat, kepemimpinan kolaboratif yang sukses tergantung dari kualitas hubungan. Dua pandangan terakhir menyiratkan bahwa hubungan dan kerja sama yang terjadi bukan hanya sekedar berbagi keuntungan dan informasi tetapi dalam rangka mewujudkan visi bersama, sehingga penerapan kepemimpinan kolaboratif akan menciptakan dan memgembangkan budaya kolaboratif.

Penerapan kepemimpinan kolaboratif pada kenyataannya mempunyai hambatan-hambatan. Oleh karenanya, penting bagi pemimpin organisasi untuk memahami dan mencari solusi atas hambatan yang terjadi. Hambatan-hambatan tersebut misalnya terkait dengan proses kolaborasi yang 
bisa memakan waktu lama dan sering bertentangan dengan sturktur organisasi tradisional. Hambatan lain berupa ketidaksepakan tujuan diantara pemimpin. Buruknya komunikasi internal organisasi karena dibatasi oleh heirarki organisasi juga bisa menjadi hambatan. Dari sisi individu, hambatan yang terjadi terkait keyakinan, nilai dan perilaku misalnya adanya arogansi, ketakutan dan kekuasaan (Wilson, 2013).

Hasil penelitian Hsieh dan Liou (2018) menunjukkan bahwa dimensi kepemimpinan kolaboratif yang terdiri dari mengaktifkan bantuan sumber daya, membingkai lingkungan kerja dan mensintesis proses kolaboratif dapat mempengaruhi kinerja organisasi. Hasil yang sama juga ditunjukkan oleh penelitian Maalouf (2019) bahwa kepemimpinan kolaboratif dapat mendorong kinerja organisasi agar dapat tetap kompettitf dan bertahan serta berdampak pada keseluruhan organisasi. Demikian juga penelitian Sulaiman (2020) menyimpulkan bahwa kepemimpinan kolaboratif memberi kontribusi positif terhadap kekompakan organisasi.

Penelitian terkait kepemimpinan kolaboratif di sekolah telah dilakukan oleh Samriangjit et al. (2016) dan menyimpulan bahwa kepemimpinan kolaboratif bermanfaat dalam meningkatkan pembelajaran dan prestasi siswa, terciptanya budaya hubungan kerja yang baik, kepedulian terhadap siswa lebih kuat, pertukaran informasi, pengetahuan dan wawasan. Sedang penelitian Mccarthy et al. (2011) menyimpulkan bahwa kepemimpinan yang mendorong kolaborasi mampu mengatasi hambatan yang ada bahkan bermanfaat terhadap penciptaan budaya positif sekolah.

Dampak kepemimpinan kolaboratif ditingkat karyawan ditunjukkan oleh hasil penelitian Maalouf (2018) bahwa kepemimpinan kolaboratif dapat bermanfaat bagi karyawan dan mampu mendorong inovasi serta secara keseluruhan mempengaruhi pembelajaran organisasi. Di lingkungan sekolah, kepemimpinan kolaboratif mampu meningkatkan produktivitas guru dan komitmen bersama (Keiser et al., 2011). Penelitian Veale (2010) menyimpulkan bahwa penerapan kepemimpinan kolaboratif di sekolah menyebabkan karyawan/staff lebih termotivasi untuk melayani siswa dengan baik, hal ini dimungkinkan karena karyawan merasa puas dengan lingkungan kerja dan hubungan antar karyawan yang mendukung.

Penelitian Crum et al. (2010) dan Chance dan Segura (2009) terkait penerapan kepemimpinan kolaboratif dengan melibatkan staff dan guru dalam langkah-langkah pengambilan keputusan untuk pengembangan pembelajaran menyimpulkan bahwa penerapan tersebut berkontribusi pada peningkatan prestasi siswa. Penelitian lain terkait pengaruh kepemimpinan kolaboratif dilakukan oleh Hallinger dan Heck (2010b), disimpulkan bahwa kepemimpinan kolaboratif berpengaruh signifikan terhadap prestasi siswa maupun kapasitas sekolah. Peningkatan tersebut lebih besar manakala kepala sekolah melibatkan staff dan pemangku kepentingan untuk bekerja sama dalam perbaikan sekolah.

\section{METODE PENELITIAN}

Metode tinjauan literatur digunakan dalam analisis dalam penelitian ini. Tinjauan literatur digunakan untuk memberi gambaran, rangkuman, evaluasi, klarifikasi, dan atau integrasi isi terhadap temuan yang telah dilakukan sebelumnya (Cooper, 1988), menghubungkan temuan terkini dengan temuan yang telah dilakukan sebelumnya, memberi simpulan umum terhadap temuan lintas bidang ilmu (Randolph, 2009). Tinjauan literatur penelitian ini mengacu pada langkah-langkah yang dikembangkan oleh Cronin, Ryan, \& Coughlan (2008). Pertama-tama menentukan topik dan mencari lieratur yang relevan. Setelah literatur dikumpulkan, dibaca dan dianalisis selanjutnya menulis ulasan yang ditemukan. Terakhir adalah referensi.

Data dikumpulkan dengan teknik kepustakaan, berupa hasil penelitian sebelumnya dalam bentuk jurnal ilmiah atau bentuk publikasi lain maupun berupa buku. Dalam penelitian ini definisi kepemimpinan kolaboratif mengacu pada pendapat Lawrence (2017) yaitu suatu kepemimpinan yang ditandai dengan visi dan nilai bersama, saling ketergantungan dan tanggung jawab bersama, saling menghormati, empati, ambiguitas, komunikasi yag efektif dan sinergi. 


\section{HASIL PENELITIAN DAN PEMBAHASAN}

Penelitian-penelitian yang telah dilakukan menunjukkan bahwa penerapan kepemimpinan kolaboratif berdampak positif pada karyawan/guru dan siswa selanjutnya akan berdampak pada sekolah secara keseluruhan disajikan pada tabel 2 .

Tabel 2. Dampak Kepemimpinan Kolaboratif

\begin{tabular}{ll}
\hline \multicolumn{1}{c}{ Pada } & \multicolumn{1}{c}{ Dampak } \\
\hline Guru & Meningkatkan produktivitas dan komitmen bersama (Keiser et al., \\
& 2011), terciptanya pertukaran informasi, pengetahuan dan \\
& wawasan (Samriangjit et al., 2016) \\
Siswa & Meningkatkan pembelajaran dan prestasi siswa (Samriangjit et al., \\
& 2016), peningkatan prestasi siswa (Chance dan Segura, 2009; Crum \\
et al., 2010; Hallinger dan Heck, 2010b) \\
Organisasi/Sekolah \\
& $\begin{array}{l}\text { Berpengaruh terhadap kapasitas sekolah (Hallinger dan Heck, } \\
\text { 2010b), terciptanya budaya hubungan kerja yang baik (Samriangjit }\end{array}$ \\
& et al., 2016), bermanfaat bagi pembelajaran organisasi (Maalouf, \\
& 2018), mempengaruhi kinerja organisasi (Hsieh dan Liou (2018); \\
& Maalouf (2019), berkontribusi positif terhadap kekompakan \\
& organisasi (Sulaiman, 2020) \\
Staff/Karyawan & Lebih termotivasi melayani siswa dengan baik (Veale, 2010), \\
& peningkatan kepedulian terhadap siswa (Samriangjit et al., 2016), \\
& mampu mendorong motivasi karyawan (Maalouf, 2018) \\
\hline
\end{tabular}

Sumber : Referensi terkait

Berdasarkan hasil penelitian (tabel 2), menunjukkan bahwa penerapan kepemimpinan kolaboratif oleh kepala sekolah berdampak positif bagi karyawan, guru, siswa dan sekolah, maka diperlukan strategi untuk menciptakan kepemimpinan kolaboratif yaitu (1) menciptakan waktu untuk kolaborasi agar pemangku kepentingan dapat menilai masalah, menetapkan tujuan bersama, membuat rencana, merefleksikan dan mengembangkan praktik serta memperdalam hubungan, (2) memprioritaskan proses agar anggota organisasi terlibat secara jujur dan konstruktif dalam pemecahan masalah melalui dialog terbuka, refleksi kolektif dan praktik yang lebih baik, (3) membuat struktur dan peran yang berguna bagi pemangku kepentingan untuk mempertahankan partisipasi dan mengembangkan kepemimpinan, (4) berkomitmen pada pengembangan kepemimpinan dengan membangun kapasitas anggota dan pemangku kepentingan agar terlibat dalam meningkatkan pembelajaran (Daniel, 2017). Dalam hal ini, Wilson (2013) menyimpulkan bahwa ada 5 (lima) elemen kunci dalam kepemimpinan kolaboratif yaitu memanfaatkan kecerdasan kolektif, mengembangkan kepercayaan, memaksimalkan bakat dan sumber daya, berbagi pengaruh dan kekuasaan serta mempercepat inovasi.

Ada 4 perspektif penting dalam membangun praktik kepemimpinan kolaboratif menurut Raelin (2006) yaitu : perspektif pertama, pemimpin harus memahami bahwa ada lebih dari satu pimpinan pada waktu yang sama sehingga pemimpin dengan sukarela berbagi kekuasaan dengan orang lain. Perspektif kedua yaitu kepemimpinan kolaboratif tidak hanya kepemimpinan bersama tetapi juga kepemimpinan kolektif. Artinya bahwa kepemimpinan tidak berasal dari pengaruh individu, tetapi berasal dari proses orang-orang yang bekerja bersama untuk tujuan yang sama. Perspektif ketiga yaitu kepemimpinan kolaboratif adalah saling menguntungkan. Artinya semua anggota organisasi dapat mengendalikan dan berkomunikasi untuk kebaikan bersama. Sedang perspektif yang terakhir yaitu kepemimpinan kolaboratif adalah kepemimpinan penuh kasih. Artinya pemimpin menjaga martabat dan menghargai setiap anggota organisasi.

Disisi lain, Hopkins et al. (2011) menjelaskan bahwa agar tujuan yang telah disepakati bersama tercapai, maka kepemimpinan kolaboratif perlu mengembangkan visi, memiliki keterampilan 
interpersonal dan manajerial serta percaya diri dalam mendorong terjadinya kolaborasi. Hal penting yang perlu diperhatikan adalah visi harus diciptakan dan dikembangkan secara bersama. Ketersediaan dan pengalokasian sumber daya secara adil juga perlu diperhatikan oleh pemimpin.

Keberhasilan penerapan kepemimpinan untuk mengatasi situasi yang komplek dipengaruhi oleh pengalaman dan ketrampilan. Ada 3 (tiga) seperangkat ketrampilan yang harus dimiliki oleh kepala sekolah adalah (1) keterampilan memediasi, pemimpin harus mampu menangai secepat mungkin konfilk secara konstruktif dan efektif, (2) keterampilan mempengaruhi, pemimpin harus mampu memilih pendekatan terbaik untuk mempengaruhi orang, memahami budaya organisasi dan kepribadian orang serta menganalisis secara obyektif terhadap situasi yang terjadi, (3) ketrampilan melibatkan orang lain, pemimpin harus mampu membangun jaringan, hubungan dan komunikasi serta melibatkan orang lain dalam pengambilan keputusan pada waktu yang tepat (Archer dan Cameron, 2013). Selanjutnya, selain ketiga keterampilan tersebut, pemimpin kolaboratif juga harus memiliki sifat agility, kesabaran dan empati. Kepala sekolah juga perlu menekankan bahwa kolaborasi terjadi antar organisasi maupun antar individu dengan kelompok dalam organisasi dan perlu memastikan kolaborasi yang baik terjadi agar tujuan bersama dan keberhasilan organisasi dapat tercapai (Hsieh dan Liou, 2018). Sedang Wilson (2013) mendidentifikasi keberhasilan penerapan kepemimpinan kolaboratif tergantung dari terciptanya lingkungan saling percaya, menghormati dan keterlibatan serta kontribusi semua pihak untuk mencapai tujuan.

Sanaghan dan Lohndorf (2015) menyarankan bahwa dalam penerapan keemimpinan kolaboratif, ada beberapa hal yang perlu diperhatikan, yaitu :

1. Heirarki. Struktur organisasi sekolah yang pada umumnya vertikal akan menyebabkan arus informasi berjalan lambat, kurang gesit, kurang fleksibel dan kurang proaktif terhadap peluang dan tantangan sehingga menghambat kerja kolaboratif.

2. Budaya organisasi. Pemimpin perlu memahami budaya organisasi misalnya terkait bagaimana keputusan dibuat, bagaimana konflik dikelola, bagaimana kekuasaan digunakan dan bagaimana kesuksesan dan kegagalan dihargai.

3. Kapasitas anggota senior dalam organisasi. Hanya anggota senior yang mempunyai kapasits yang dilibatkan dalam proses kolaboratif.

4. Networking. Networking yang luas akan membantu mekanisme kolaboratif menjadi kuat, yang memumgkinkan pemangku kepentingan mampu melintasi batas kelembagaan dan bekerja sama dalam pencapaian tujuan organisasi.

5. Membatasi kolaborasi sesuai keperluan agar lebih efektif.

Kepemimpinan kolaboratif tidak hanya diciptakan, dibangun dan diimplementasikan, tetapi lebih dari itu, implementasinya perlu juga dikelola. Hsieh dan Liou (2018) menjelaskan bahwa pengelolaan tersebut dilakukan melalui kegiatan kolaboratif seperti (1) mengaktifkan bantuan sumber daya melalui identifikasi dan penggabungan sumber daya dalam mencapai tujuan bersama, (2) membingkai lingkungan kerja melalui peran pimpinan dalam mempengaruhi individu membangun dan menjaga komitmen untuk tujuan bersama, (3) memobilisasi dukungan pemangku kepentingan dengan melibatkan pemangku kepentingan baik internal maupun eksternal untuk keberhasilan program dan (4) mensintesis proses kolaboratif melalui peran pimpinan dalam menciptakan dan memelihara proses kolaboratif.

\section{KESIMPULAN}

Berdasarkan hasil penelitian, kepemimpinan kolaboratif memiliki dampak positif terhadap karyawan, guru, siswa dan sekolah. Untuk itu, perlu mendapat perhatian terkait penerapan kepemimpinan kolaboratif yaitu kepala sekolah perlu melibatkan dan menyelaraskan anggota organisasi serta memfokuskan tim untuk mencapai visi bersama, kepala sekolah lebih menggunakan kekuatan pengaruh dari pada kekuatan otoritas. Kepemimpnan kolaboratif berfokus pada membangun kepercayaan, berbagi kekuasaan dan mengembangkan orang dalam suatu organisasi. Sehingga kepemimpinan kolaboratif didasarkan pada semua anggota organisasi (guru, karyawan) bisa menjadi lebih pintar, kreatif dan kompeten agar tujuan akhir pendidikan tercapai. 


\section{DAFTAR PUSTAKA}

Anfara, V. A., Pate, P. E., Caskey, M. M., Andrews, P. G., \& Daniel, L. G. (2008). Research Summary : Courageous, Collaborative Leadership.

Ansell, C., \& Gash, A. (2008). Collaborative Governance in Theory and Practice. Journal of Public Administration Research and Theory, 18(4), 543-571. https://doi.org/10.1093/jopart/mum032

Ansell, C., \& Gash, A. (2012). Stewards, Mediators, and Catalysts : Toward a Model of Collaborative Leadership. The Innovation Journal, 17(1), 1-21.

Archer, D., \& Cameron, A. (2013). The Future Collaborative Leader. In Collaborative Leadership: Building Relationships, Handling Conflict and Sharing Control (pp. 1-17). Retrieved from http://www.socia.co.uk/knowledge/Publications.aspx

Burgaz, B., \& Turan, S. (2015). The Features of Schools which Conducted a Comenius Project and Evaluation of Features in Terms of Collaborative Leadership Characteristics. Procedia - Social and Behavioral Sciences, 174, 338-346. https://doi.org/10.1016/j.sbspro.2015.01.670

Bush, T., \& Glover, D. (2003). School Leadership : Concepts and Evidence. National College for School Leadership. Oxford, United Kingdom.

Bush, T., \& Glover, D. (2014). School Leadership Models: What Do We Know? School Leadership and Management, 34(5), 553-571. https://doi.org/10.1080/13632434.2014.928680

Chance, P. L., \& Segura, S. N. (2009). A Rural High School' s Collaborative Approach to School Improvement. Journal of Research in Rural Education, 24(5), 1-12.

Crum, K. S., Sherman, W. H., \& Myran, S. (2010). Best Practices of Successful Elementary School Leaders. Journal of Educational Administration, 48(1), 48-63.

https://doi.org/10.1108/09578231011015412

Daniel, J. (2017). Strong Collaborative Relationships for Strong Community Schools. National Education Policy Center. Retrieved from http://libproxy.library.wmich.edu/login?url=https://search.proquest.com/docview/201126324 5 ?accountid=15099\%0Ahttps://primopmtna01.hosted.exlibrisgroup.com/openurl/01WMU/01WMU?url_ver=Z39.882004\&rft_val_fmt=info:ofi/fmt:kev:mtx:book\&genre=report\&sid=ProQ

Daniëls, E., Hondeghem, A., \& Dochy, F. (2019). A Review on Leadership and Leadership Development in Educational Settings. Educational Research Review, 27, 110-125. https://doi.org/10.1016/j.edurev.2019.02.003

Day, C., \& Sammons, P. (2013). Successful Leadership: A Review of the International Literature. CfBT Educational Trust.

Edwards, G., \& Smit, B. (2008). Collaborative Leadership as a Necessary Condition for Successful Curriculum Implementation. Journal of Education, (44), 109-122.

Finh, F. (1977). Collaborative Leadership in Work Settings. The Journal of Applied Behavioral Science, 13(3), 292-302.

Grissom, J. A., \& Loeb, S. (2011). Triangulating Principal Effectiveness: How Perspectives of Parents, Teachers, and Assistant Principals Identify the Central Importance of Managerial Skills. American Educational Research Journal (Vol. 48). https://doi.org/10.3102/0002831211402663

Hallinger, P. (1992). The Evolving Role of American Principals: From Managerial to Instructional to Transformational Leaders. Journal of Educational Administration, 30(3), 35-48. https://doi.org/10.1108/09578239210014306

Hallinger, P., \& Heck, R. H. (2010a). Collaborative Leadership and School Improvement: Understanding the Impact on School Capacity and Student Learning. School Leadership and Management, 30(2), 95-110. https://doi.org/10.1080/13632431003663214

Hallinger, P., \& Heck, R. H. (2010b). Leadership for Learning : Does Collaborative Leadership Make a Difference in School Improvement ?, 38(6), 654-678.

https://doi.org/10.1177/1741143210379060

Heck, R. H., \& Hallinger, P. (2005). The Study of Educational Leadership and Management: Where 
Does the Field Stand Today? Educational Management Administration \& Leadership, 33(2), 229-244. https://doi.org/10.1177/1741143205051055

Hitt, D. H., \& Tucker, P. D. (2016). Systematic Review of Key Leader Practices Found to Influence Student Achievement: A Unified Framework. Review of Educational Research, 86(2), 531-569. https://doi.org/10.3102/0034654315614911

Hopkins, D., Johnson, V., Damico, S., \& Wepner, S. (2011). Emerging Characteristics of Education Deans' Collaborative Leadership. Academic Leadership: The Online Journal, 9(1).

Hsieh, J. Y., \& Liou, K. T. (2018). Collaborative Leadership and Organizational Performance: Assessing the Structural Relation in a Public Service Agency. Review of Public Personnel Administration, 38(1), 83-109. https://doi.org/10.1177/0734371X15623619

Jäppinen, A.-K. (2013). Collaborative Leadership as the Lens for Co-Creating an Innovation - A Curriculum Reform in Management Education. In R. Smeds \& O. Irrmann (Eds.), Co-Create 2013: The Boundary-Crossing Conference on Co-Design in Innovation Publication (pp. 213-224). Aalto University.

Jäppinen, A. K., \& Ciussi, M. (2016). Indicators of Improved Learning Contexts: A Collaborative Perspective on Educational Leadership. International Journal of Leadership in Education, 19(4), 482-504. https://doi.org/10.1080/13603124.2015.1015616

Keiser, N., Kincaid, M., \& Servais, K. (2011). Using a Collaborative Leadership Model in a Teacher Education Program. American Journal of Educational Studies, 4(1), 5-21.

Lawrence, R. L. (2017). Understanding Collaborative Leadership in Theory and Practice. In Adult Learning Through Collaborative Leadership (pp. 89-96). Wiley Online Library. https://doi.org/10.1002/ace.20262

Lazaridou, A., \& Iordanides, G. (2011). The Principar's Role in Achieving School Effectiveness. International Studies in Educational, 39(3), 3-20.

Leithwood, K., Harris, A., \& Hopkins, D. (2019). Seven Strong Claims about Successful School Leadership Revisited. School Leadership and Management, 40(1), 5-22. https://doi.org/10.1080/13632434.2019.1596077

Maalouf, G. (2018). A Causal Relationship between Collaborative Leadership and Innovation. Arabian Journal of Business and Management Review, 8(1), 1-8.

Maalouf, G. Y. (2019). Effects of Collaborative Leadership on Organizational Performance. International Journal of Multidisciplinary Research and Development, 6(1), 138-144. https://doi.org/10.22271/ijmrd.2019.v6.i1.25

Mccarthy, P. J., Brennan, L., \& Vecchiarello, K. (2011). Parent - School Communication in the Inclusive Classroom : A Comprehensive Model of Collaboration in Education. International Journal of Humanities and Social Science, 1(15), 55-60.

Meyer, A. De. (2009). Collaborative Leadership. Judge Business School, University of Cambridge.

Raelin, J. (2006). Does Action Learning Promote Collaborative Leadership? Academy of Management Learning and Education, 5(2), 152-168.

Robinson, V. M. J., Lloyd, C. A., \& Rowe, K. J. (2008). The Impact of Leadership on Student Outcomes: An Analysis of the Differential Effects of Leadership Types. Educational Administration Quarterly, 44(5), 635-674. https://doi.org/10.1177/0013161X08321509

Samriangjit, P., Tesaputa, K., \& Somprach, K. (2016). Strengthening Collaborative Leadership for Thai Primary School Administrators. International Education Studies, 9(4), 42-53. https://doi.org/10.5539/ies.v9n4p42

Sanaghan, B. P., \& Lohndorf, J. (2015). Collaborative Leadership: The New Leadership Stance. In Collaborative Leadership in Higher Education (pp. 6-37). Academic Impressions.

Schlebusch, G. J. (2020). Collaborative Leadership and Sustained Learner Academic Performance in Secondary Schools: A Blaming Game? Africa Education Review, 17(3), 74-89. https://doi.org/10.1080/18146627.2019.1635498

Spillane, J. P., Halverson, R., \& Diamond, J. B. (2007). Towards a Theory of Leadership Practice. In I. Westbury \& G. Milburn (Eds.), Rethinking Schooling (1st ed., pp. 196-230). New York: 
Routledge. https://doi.org/10.4324/9780203963180

Sulaiman, I. F. (2020). Collaborative Leadership Style Among Administrative Assistants of Two Faculties At International Islamic University Malaysia. Humanities \& Social Sciences Reviews, 8(2), 495-506. https://doi.org/10.18510/hssr.2020.8257

Veale, N. W. (2010). A Comparison Between Collaborative and Authoritative Leadership Styles of Special Education Administrators. Journal of the American Academy of Special Education Professionals., 147-156. Retrieved from https://eric.ed.gov/contentdelivery/servlet/ERICServlet?accno=EJ1137054

Wilson, S. (2013). Collaborative Leadership: It's Good to Talk. British Journal of Healthcare Management, 19(7), 335-337.

\section{Peraturan}

Peraturan Menteri Pendidikan dan Kebudayaan Republik Indonesia Nomor 6 tahun 2018 tentang Penugasan Guru sebagai Kepala Sekolah.

\section{Website}

https://www.depoedu.com/2020/09/07/edu-talk/menyambut-kurikulum-baru-dan-merdekabelajar-di-tahun-ajaran-2021-2022. Diakses 18 November 2020. 10.45

https://www.liputan6.com/news/read/4347861/merdeka-belajar-di-tengah-pandemi-kemendikbudterbitkan-kurikulum-darurat. Diakses 18 November 2020. 11.00 